\title{
Estimation of The Shear-Lag Effect of Composite Box Girder Bridges With Corrugated Steel Webs
}

\author{
Ruijuan Jiang, Qiming Wu, Yufeng Xiao, Manlin Peng and Tianhua $\mathrm{Xu}^{*}$
}

Shenzhen Municipal Design and Research Institute Co. Ltd., P.R. China

\begin{abstract}
The shear-lag effect refers to the non-uniform normal stress distribution on a box girder cross section induced by the shear flow at the flanges and the webs. It can be observed in all kinds of box girder structures especially the ones with a large width. The shear-lag effect has to be appropriately considered in bridge design, otherwise the servicability and reliability of a bridge will be reduced. In this paper, a semi-analytical method is proposed to estimate the shear-lag effect for composite box girder bridges with corrugated steel webs. Three generalized displacement functions are first introduced to represent the deformation patterns in different parts of a bridge cross section. Afterwards, the governing equations of the problem are derived based on the energy variance principle considering the feature of a composite box girder bridge with corurgated steel webs and then solved using the finite difference method. The shear-lag effect of a continuous girder bridge constructed in South China is investigated based on the proposed semi-analytical method and finite element simulation. The results show that the proposed semi-analytical method is able to well estimate the characteristics of the example bridge. Given the same bridge cross section, the magnitude of the shear-lag effect at different parts of the example bridge is inversely proportional to the effective span length.
\end{abstract}

Keywords: Energy-based semi-analytical method; Composite box girder bridges; Shear-lag effect; Corrugated steel webs

\section{Introduction}

The composite box girder with corrugated steel webs is a new type of composite bridge structure (Figure 1). It usually composes of top and bottom concrete slabs, corrugated steel webs and internal and external prestressing tendons. Compared to conrete box girders, this kind of structure has a smaller self-weight, a better seismic performance and a lower construction cost [1]. As the flexural stiffness of the webs can be neglected due to the so-called "accordion effect", the bending of the girder is mainly resisted by the top and bottom concrete slabs. The corrugated steel webs, on the other hand, carry most of the shear force. Therefore, both the concrete and the steel can be utilized efficiently.

Similar to a concrete box girder, the shear-lag effect can also be observed in a composite box girder with corrugated steel webs, especially in that with wide flanges. The shear-lag effect refers to the non-uniform normal stress distribution on a box girder cross section induced by the shear flow at the flanges and the webs. Although extensive studies have been carried out for the mechanical performance such as the flexural, shearing and torsional behavior of composite box girders with corrugated steel webs [2-7], the research on the shear-lag effect is still limited [8-10]. As a promising analytical tool, the energy-based method has been used to analyze the shear-lag effect [9-11]. However, only one generalized displacement function was used in existing researches, which cannot represent the different deformation patterns at different parts of a cross section.

This paper aims to investigate the shear-lag effect of composite box girders with corrugated steel webs. The concept of the effective flange

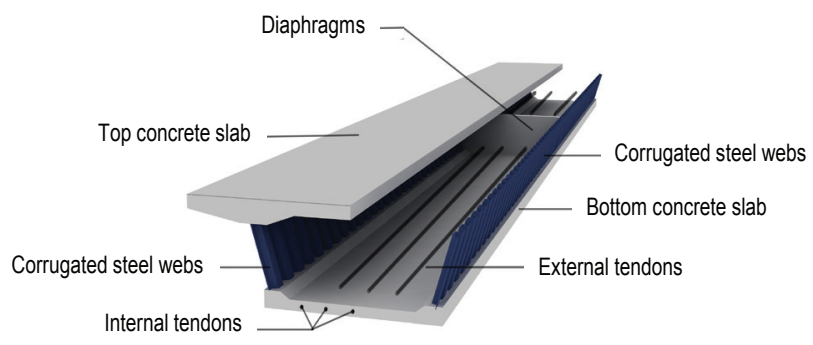

Figure 1: A composite box girder with corrugated steel webs. width coefficient, which is an effective indicator of the shear-lag effect, will be first introduced. Then an energy-based semi-analytical method adopting three generalized displacement functions will be developed to estimate the effective flange width coefficient. A real bridge in South China will be investigated afterwards to verity the proposed semi-analytical method and preliminary analyze the characteristics of the shear-lag effect of a continuous composite box girder bridge with corrugated steel webs.

\section{Research Methodhology}

\section{Effective flange width coefficient}

In engineering practice, the shear-lag effect is often considered by adopting an "effective flange width" in the calculation based on the elementary beam theory [12-14]. The conventional definitions of the effective flange width adopted in existing design codes or research papers are only applicable for flanges with a uniform thickness, and the non-uniform distribution of the cross-sectional stress is usually neglected [15]

As an improvement to the concept of effective flange width, Jiang et al. [15] suggested that the effective flange width be calculated by:

$$
b_{e i}=\frac{\iint_{A_{i}} \sigma_{x i}(y, z) \mathrm{d} A}{\int_{t_{a i}} \sigma_{x i}\left(y_{b i}, z\right) \mathrm{d} s}
$$

where $b_{e i}$ and $b_{i}$ are the effective and the atcural flange width of $A$ corresponding to $A_{i}$ in Figure 2, respectively; $t_{a j}$ is the average thickness defined as $t_{a i}=A_{i} / b_{i}$; and $y_{b i}$ is the $y$-coordinate of the intersection point between the concrete slab and the web; $\sigma_{x i}()$ is the normal stress at the location corresponding to the coordinates given in the bracket at the

*Corresponding author: Tianhua Xu, Shenzhen Municipal Design and Research Institute Co. Ltd., Shenzhen 518029, P.R. China, Tel: +86-758-83326740; E-mail: xuth@szmedi.com.cn

Received April 26, 2018; Accepted August 03, 2018; Published August 08, 2018

Citation: Jiang R, Wu Q, Xiao Y, Peng M, Xu T (2018) Estimation of The ShearLag Effect of Composite Box Girder Bridges With Corrugated Steel Webs. J Civil Environ Eng 8: 319. doi: 10.4172/2165-784X.1000319

Copyright: ( $) 2018$ Jiang R, et al. This is an open-access article distributed under the terms of the Creative Commons Attribution License, which permits unrestricted use, distribution, and reproduction in any medium, provided the original author and source are credited. 


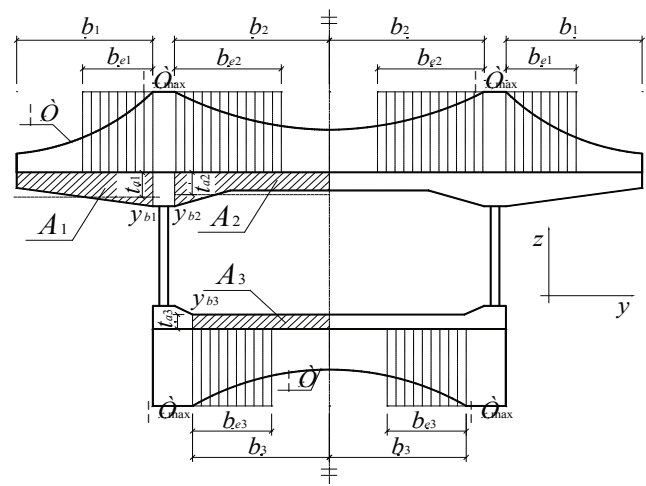

Figure 2: Typical cross section of a composite box girder bridge with corrugated steel webs and schematic diaphragm of normal stress distribution.

area $A_{i} ; \mathrm{d} A$ and $\mathrm{d} s$ are the infinitesimal area and segment, respectively. The integration at the numerator is carried out over $A_{i}$, while the integration at the denominator is carried out along the vertical line $y=y_{b i} . x, y$ and $z$ directions are the longitudinal, transverse and vertical directions, respectively.

The definition of the effective flange width in Eq. (1) is superior to the conventional definitions. With the use of the stress integration in the numerator, the non-uniform distribution of the cross-sectional normal stress can be considered. The average thickness is adotpted in the denominator, so it is applicable to cross sections with thicknessvarying flanges.

With the definition of the effective flange width in Eq.(1), the effective flange width coefficient can be defined as $\rho_{i}=b_{e i} / b_{i} \cdot \rho_{i}$ is able to represent the characteristics of the shear-lag effect. When $\rho_{i}$ is smaller than 1.0, the shear-lag effect can be regarded as positive. In this case, the effective flange width is lager than the actural flange width because the cross-sectional normal stress at the intersection between the flange and the web is larger than that at other locations. On the other hand, when $\rho_{i}$ is larger than 1.0, the shear-lag effect can be regarded as negative. The magnitude of the shear-lag effect can also be indicated by $\rho_{i}$. When the magnitude of the shear-lag effect gets stronger, the value of $\rho_{i}$ will get farther away from 1.0. Therefore, in this research, the effective flange width coefficient defined according to Eq. (1) is used as an indicator of the shear-lag effect.

\section{Energy-based semi-analytical calculation method}

According to the elasticity theory, the cross-sectional normal stress $\sigma_{x i}$ is related to the corresponding longitudinal displacement $u_{i}$ at each of the area $A_{i}$ :

$$
\sigma_{x i}=E \frac{\partial u_{i}(x, y, z)}{\partial x}
$$

\section{Assume $u_{i}$ can be expressed by}

$$
u_{i}(x, y, z)=z\left[-\frac{\mathrm{d} w}{\mathrm{~d} x}+\left(1-\frac{y^{3}}{b_{i}^{3}}\right) U_{i}(x)\right] \quad(i=1,2,3)
$$

where $w=w(x)$ is the deflection of the beam; $U_{i}$ is the generalized displacement function at $A_{i}$, which is the maximum differences of the shear rotation angle at each part of the cross section. $U_{1}, U_{2}$ and $U_{3}$ are different functions representing the deformation patterns of different parts of a cross section.

Then the global potential energy, $\Pi$, of a composite box girder with corrugated steel webs can be written as follows:

$$
\Pi=\int M(x) w^{\prime \prime} \mathrm{d} x+\sum_{i=1}^{3}\left\{\frac{1}{2} \int E I_{i}(x)\left[w^{\prime \prime 2}-\frac{3}{2} U_{i}^{\prime} w^{\prime \prime}+\frac{9}{14} U_{i}^{\prime 2}+\frac{9}{5} \frac{G}{E} \frac{1}{b_{i}^{2}} U_{i}^{2}\right] \mathrm{d} x\right\}
$$

where $M(x)$ is the internal bending moment induced by external loadings; $E$ and $G$ are the elastic shear modulus of concrete, respectively; $I_{i}(x)$ is the moment of inertia of $A_{i}$. A variable with an apostrophe (') represents its derivative along the longitudinal direction $(\mathrm{d} / \mathrm{d} x)$. The first term on the right-hand-side of Eq. (4) is the potential energy induced by external loadings. The second term is the sum of the compressional and shearing energy at $A_{i}$. The strain energy of the webs is not considered as the flexural rigidity of the webs is neglible due to the so-called "accordion effect". Take the variance of Eq. (4):

$$
\begin{aligned}
\ddot{\mathrm{a}} \Pi= & \ddot{\mathrm{a}}\left\{\int M(x) w^{\prime \prime} \mathrm{d} x\right\}+\sum_{i=1}^{3}\left(\ddot{\mathrm{a}}\left\{\frac{1}{2} \int E I_{i}(x)\left(w^{\prime \prime 2}-\frac{3}{2} w^{\prime \prime} U_{i}^{\prime}+\frac{9}{14} U_{i}^{\prime 2}+\frac{9 G U_{i}^{2}}{5 E b_{i}^{2}}\right) \mathrm{d} x\right\}\right) \\
= & \int\left[M(x)+E \sum_{i=1}^{3} I_{i}(x) w^{\prime \prime}-\frac{3}{4} E \sum_{i=1}^{3}\left(I_{i}(x) U_{i}^{\prime}\right)\right] \ddot{a} w^{\prime \prime} \mathrm{d} x \\
& +\sum_{i=1}^{3}\left(\int E I_{i}(x)\left(-\frac{3}{4} w^{\prime \prime}+\frac{9}{14} U_{i}^{\prime}\right) \ddot{\mathrm{a}} U_{i}^{\prime} \mathrm{d} x\right)+\frac{9 G}{5} \sum_{i=1}^{3}\left(\int \frac{I_{i}(x) U_{i}}{b_{i}^{2}} U_{i} \mathrm{~d} x\right)
\end{aligned}
$$

According to the principle of minimum potential energy, let $\delta \Pi=0$, and then Eq. (6) can be obtained after some algebraic operation:

$$
\begin{aligned}
& \int\left[M(x)+E \sum_{i=1}^{3}\left(I_{i}(x)\right) w^{\prime \prime}-\frac{3}{4} E \sum_{i=1}^{3}\left(I_{i}(x) U_{i}^{\prime}\right)\right] \ddot{a} w^{\prime \prime} \mathrm{d} x \\
& +x E \sum_{i=1}^{3}\left(I_{i}(x)\left(-\frac{3}{4} w^{\prime \prime}+\frac{9}{14} U_{i}^{\prime}\right) \mathrm{a} U_{i}\right) \\
& -\sum_{i=1}^{3}\left[\int\left(E I_{i}(x)\left(-\frac{3}{4} w^{\prime \prime \prime}+\frac{9}{14} U_{1}^{\prime \prime}\right)+E I_{i}^{\prime}(x)\left(-\frac{3}{4} w^{\prime \prime}+\frac{9}{14} U_{i}^{\prime}\right)-I_{i}(x) \frac{9 G U_{i}}{5 b_{i}^{2}}\right) \ddot{a} U_{i} \mathrm{~d} x\right]=0
\end{aligned}
$$

Eq. (7) is valid for any given $\delta w^{\prime \prime}, \delta U_{1}, \delta U_{2}$ and $\delta U_{3}$, thus the following equations can be obtained:

$$
\begin{aligned}
& M(x)+E \sum_{i=1}^{3}\left(I_{i}\right) w^{\prime \prime}-\frac{3}{4} E \sum_{i=1}^{3}\left(I_{i} U_{i}^{\prime}\right)=0 \\
& I_{i}\left(\frac{3}{4} w^{\prime \prime \prime}-\frac{9}{14} U_{1}^{\prime \prime}+\frac{9 G U_{i}}{5 E b_{i}^{2}}\right)+I_{i}^{\prime}\left(\frac{3}{4} w^{\prime}-\frac{9}{14} U_{i}^{\prime}\right)=0 \quad(\text { for } i=1,2,3) \\
& \left.E \sum_{i=1}^{3}\left(I_{i}(x)\left(-\frac{3}{4} w^{\prime \prime}+\frac{9}{14} U_{i}^{\prime}\right) \ddot{a} U_{i}\right)\right|_{x_{1}} ^{x_{2}}=0 \quad(\text { for } i=1,2,3)
\end{aligned}
$$

Equations (7) and (8) are the governing differential equations for the deflection and the generalized displacements, while Eq. (9) is the boundary condition that has to be satisfied at the interval $\left(x_{1}, x_{2}\right)$.

The governing equations can be solved using finite difference method. First the investigated girder is discretized using finite difference nodes. The 1st- and 2 nd-order derivatives of $U_{i}$ at the $j$ th node can be represented by the nodal values $U$ :

$$
\left(\frac{\mathrm{d} U_{i}}{\mathrm{~d} x}\right)_{j}=\frac{U_{i, j+1}-U_{i, j-1}}{2 a} \text { for } i=1,2,3
$$

$$
\left(\frac{\mathrm{d}^{2} U_{i}}{\mathrm{~d} x^{2}}\right)_{j}=\frac{U_{i, j+1}-2 U_{i, j}+U_{i, j-1}}{a^{2}} \text { for } i=1,2,3
$$

where $a$ is the interval between the finite difference nodes; the subscripts $j-1, j$ and $j+1$ are the number of nodes. Meanwhile, according to Equation (7), the 2nd-order derivative of $w$ can be written as

$$
w^{\prime \prime}=-\frac{M(x)}{E I}+\frac{3}{4} \frac{\sum_{i=1}^{3}\left(I_{i} U_{i}^{\prime}\right)}{I}
$$

With the substitution of Eqs. (10) (12) into Eqs. (7) and (8), the finite difference equations of the problem can be obtained. The 
generalized displacements $U_{1}, U_{2}$ and $U_{3}$ can be solved from the finite difference equations in a iterative manner, and afterwards the effective flange width coefficients can be calcualted accordingly.

\section{Results and Discussion}

\section{The shear-lag effect of a continuous girder bridge with corrugated steel webs}

To validate the proposed energy-based method and to preliminary study the shear-lag effect of a composite box girder bridge with corrugated steel webs, a real bridge constructed in South China (termed as "the example brige" in the following parts) is studied in this paper. It is a $88+156+88 \mathrm{~m}$ three-span continuous girder bridge. Figure 3 shows its typical cross section. The widths of the top and bottom concrete slabs are 16.25 and $8.7 \mathrm{~m}$, respectively. A thickness-varying cross section is adopted for the top concrete slab. Figure 4 shows a corrugation of the webs in the example bridge.

In this research, the case that the example bridge is subjected to a uniformly distributed loading is considered. The effective flange coefficients in this case were first calculated using the proposed semianalytical method. Meanwhile, finite element simulation was carried out to obtain the cross-sectional stresses of the example bridge. Then the effective flange width coefficients are calculated using the stresses obtained from the finite element simulaton. The finite element method is a computational technique used to obtain approximate solutions of boundary value problems in engineering. The main difference between the finite difference method and the finite element method is that the former is based on the approximation of higher-order terms of a derivative using lower-order terms, while the latter is developed with the interpolation of variable values in a computational domain or a numerical model.

In this research, the finite element simulation was performed using ANSYS [16], which is a universal finite element platform widely used in various areas such as civil engineering, mechanical engineering, electronic engineering and so on. The basic procedures of finite element simulation using ANSYS include specifying material properties, developing a numerical model, discretizing the model using nodes and finite elements, applying boundary and loading conditions, solving and post-processing, which are shown in Figure 5. In the finite element model in this research, the top and bottom concrete slabs were modeled using solid elements, while the webs were modeled using shell elements. All the materials were modeled as linear elastic materials with the material parameters obtained from laboratory tests.

Figure 6 shows the effective flange width coefficients for the example bridge under a uniformly distributed loading obtained using two different methods. The two kinds of results agree well with each other, indicating that the proposed semi-analytical method can well estimate the shear-lag effect of a composite box girder brige. Figure 6 a also shows the schematic diagram of the bending moment of the example bridge, and the two dashed lines in each figure demonstrates the locations where the bending moment is zero ("zero bending moment point"). At these locations, the normal stress at the bridge cross section is close to zero, thus singular values of the effective flange width coefficients may occur following the proposed definition in Eq. (1). As a result, the two kinds of results may differ from each other at these locations. However, the overall characteristics of the shear-lag effect can still be revealed by the curves in Figure 6 as the influence of the singular values is limited within a small area.

According to the curves in Figure 6, for the example bridge in this paper, the strongest shear-lag effect is observed at the positive bending moment zone at the side span, where the values $\rho_{1}, \rho_{2}$ and $\rho_{3}$ are smaller that those at other locations. At the negative bending moment zone near the intermediate support, the shear-lag effect can be neglected as the values of the effective flange widths are close to 1.0. This is because the length of the positive bending moment zone at the side span is far smaller than the length of the negative bending moment zone next to the intermediate support. Wu et al. [8] has shown that for a simply

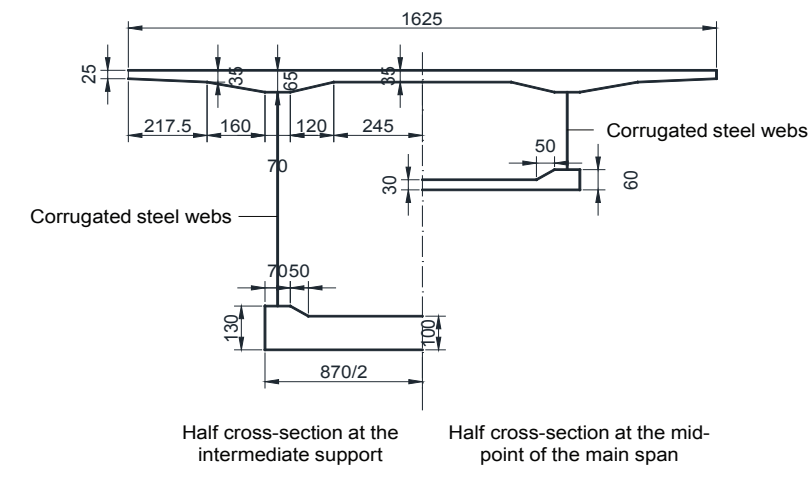

Figure 3: Typical cross section of the example bridge (unit: $\mathrm{cm}$ ).

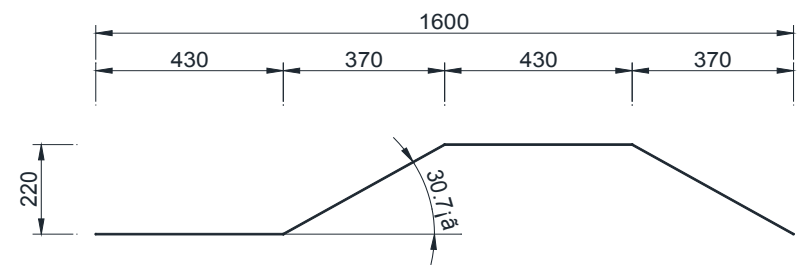

Figure 4: A corrugation of the webs in the example bridge (unit: $\mathrm{mm}$ ).

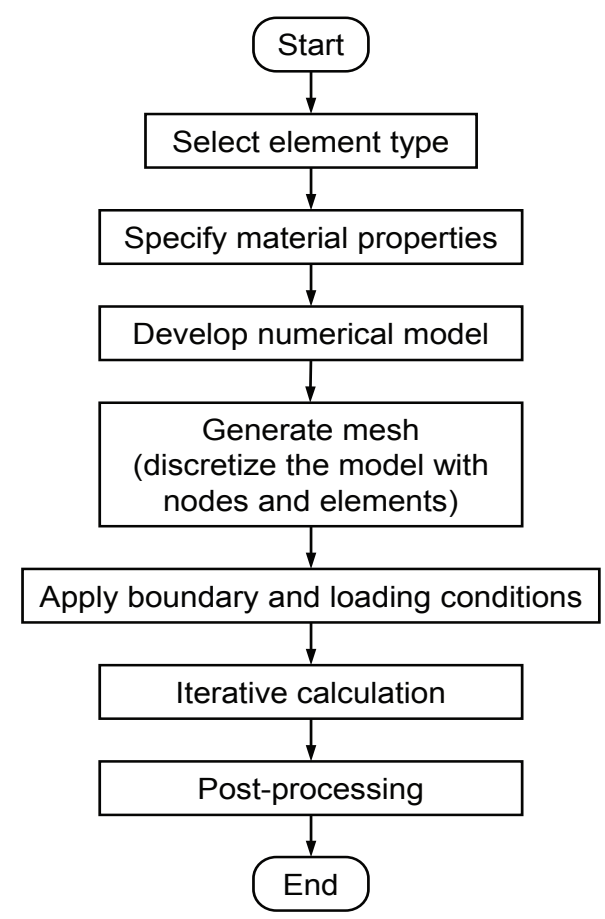

Figure 5: Flow chart of finite element simulation using ANSYS. 

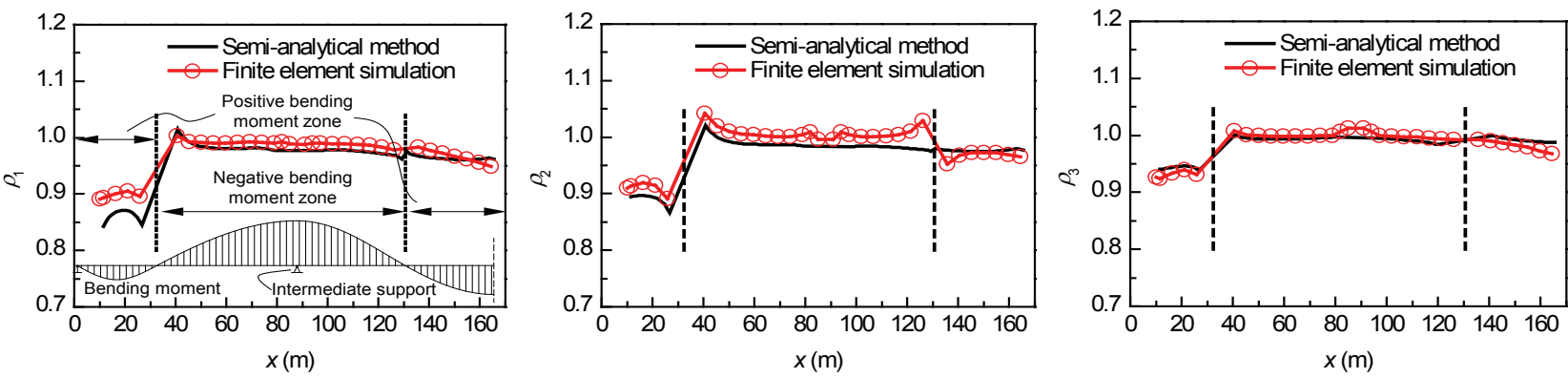

Figure 6: Coefficients of effective flange width under a uniformly distributed loading of the example bridge.

supported gider, the magnitude of the shear-lag effect will increase as the length of a span dicreases while the width of the girder is kept unchanged. For the example bridge here, the positive bending moment zone at the side span and the negative bending moment zone near the intermediate support can be viewed as a short and a relatively long simply supported girder, respectively. Each positive or negative bendong moment zone can be defined as an "effective span" of a bridge. Then the legnth between the zero bending moment points can be regarded as the "effective span length". It can be concluded from the calculation results that in a continuous girder bridge, the magnitude of the shear-lag effect increases with the decreases of the effective span length.

\section{Conclusion}

In this paper, an energy-based semi-analytical method is developed to estimate the shear-lag effect of composite box girder with corrugated steel webs. Three different generalized displacement functions are used in the proposed method, which can well take into account the different deformation patterns at different parts of a cross section. A real bridge constructed in South China is investigated as an example. For this example bridge, the effective flange width coefficients obtained from the proposed semi-analytical method agree well with those obtained from finite element simulation. The strongest shear-lag effect is observed at the positive bending moement zone at the side span because of its short effective span length. On the contrary, with a long effective span length, the negative bending moment zone near the intermediate experience weak shear-lag effect.

\section{Acknowledgements}

The authors wish to express their appreciation to the financial support from National Natural Science Foundation of China (Project No.51578323.) Guangdong Provincial Department of Science and Technology (Project No. 201202-025) and Science and Technology Innovation Committee of Shenzhen (Project No. JCYJ2014090216222).

\section{References}

1. Jiang RJ, Au FTK, Xiao YF (2015) Prestressed concrete girder bridges with corrugated steel webs: A review. J Struct Eng-ASCE 141: 04014108.

2. Chen XC, Au FTK, Bai Z, Li Z, Jiang RJ (2015) Flexural ductility of reinforced and prestressed concrete sections with corrugated steel webs. Comput Concrete 16: 625-642.

3. Chen XC, Bai Z, Zeng Y, Jiang RJ, Au FTK (2016) Prestressed concrete bridges with corrugated steel webs: Nonlinear analysis and experimental investigation. Steel Compos Struct 21: 1045-1067.

4. Chen XC, Li Z, Au FTK, Jiang RJ (2016) Flexural vibration of prestressed concrete bridges with corrugated steel webs. Int J Struct Stab Dyn 17: 1750023

5. Hassanein MF, Kharoob OF (2013) Behavior of bridge girders with corrugated webs: (II) Shear strength and design. Eng Struct 57: 544-553.

6. Hassanein MF, Kharoob OF (2014) Shear buckling behavior of tapered bridge girders with steel corrugated webs. Eng Struct 74: 157-169.

7. Ding $Y$, Jiang KB, Liu YW (2012) Nonlinear analysis for PC box-girder with corrugated steel webs under pure torsion. Thin-Walled Struct 51: 167-173.

8. Wu WQ, Wan S, Ye JS, Fang TY (2004) 3-D finite element analysis on shear lag effect in composite box girderwith corrugated steel web. China Civil Eng J 37: 31-34.

9. Li L, Peng K, Wang W (2009) Theoretical and experimental study on shear lag effect of composite box girder with corrugated steel webs. J Highway Transport Res Dev 26: 78-83.

10. Ji W, Lin P, Liu S, Wang $L$ (2010) Variational principle of shear lag effect of composite box girders with corrugated steel webs. J Lanzhou Jiaotong Univ 29: 16-19.

11. Zhou W, Jiang L, Liu Z, Liu X (2012) Closed-form solution to thin-walled box girders considering effects of shear deformation and shear lag. J Cent South Univ 19: 2650-2655

12. Ministry of Transport of the People's Republic of China (2004) JTG D62: Code for design of highway reinforced concrete and prestressed concrete bridges and culverts. Beijing: Communications Press, China.

13. AASHTO (2005) AASHTO LRFD bridge design specifications (3rd edn). Washington DC: AASHTO.

14. European Committee for Standardization (2005) Eurocode 4- Design of composite steel and concrete structures - part 2: General rules and rules for bridges. Brussels: European Committee for Standardization. EN 1994-2.

15. Jiang RJ, Xu TH, Wu QM (2016) Effective flange width for composite box girder with corrugated steel webs. Proceedings of the 2016 World Congress on Advances in Civil Environmental and Materials Research (ACEM16). Aug 28-Sep 1, Jeju, Korea. 